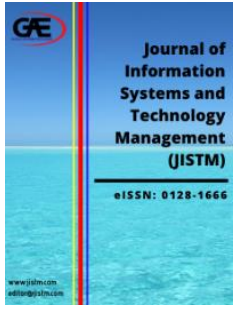

\author{
JOURNAL OF INFORMATION \\ SYSTEM AND TECHNOLOGY \\ MANAGEMENT (JISTM) \\ WWW.jistm.com
}

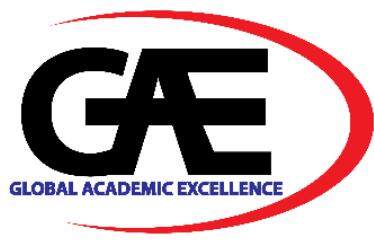

THE RELATIONSHIP BETWEEN COMPETITIVE INTELLIGENCE PROCESSES AND HOTELS' INFORMATION QUALITY: EVIDENCE FROM MALAYSIA

\author{
Akram Mufareh Alshammakh $^{1 *}$, Adi Anuar Azmin ${ }^{2}$ \\ 1 Faculty of Applied and Human Sciences, Universiti Malaysia Perlis, Malaysia, and Thamar University, Dhamar, \\ Yemen \\ Email: alshamakha@yahoo.com \\ 2 Faculty of Applied and Human Sciences, Universiti Malaysia Perlis, Malaysia \\ Email: adianuar@unimap.edu.my \\ Corresponding Author
}

\section{Article Info:}

Article history:

Received date: 15.09 .2021

Revised date: 10.10 .2021

Accepted date: 20.11 .2021

Published date: 01.12.2021

\section{To cite this document:}

Alshammakh, A. M., \& Azmin, A. A. (2021). The Relationship Between Competitive Intelligence Processes And Hotels' Information Quality: Evidence From Malaysia. Journal of Information System and Technology Management, 6 (24), 34-57.

DOI: $10.35631 /$ JISTM.624005

This work is licensed under CC BY 4.0

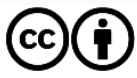

\begin{abstract}
:
The information quality (IQ) and the tools used to generate it such as competitive intelligence (CI) are the most critical competitive competencies for businesses today, particularly in the tourism and hotel sectors. However, there is still ambiguity about the impact of each phase of the competitiveintelligence process (CIP) on IQ, particularly in the hotel industry in a developing country such as Malaysia. Thus, the purpose of this research is to detect the level of IQ resulting from CIP in Malaysian hotels, as well as to investigate the impact of each phase of CIP (planning and focus, gathering, analysis, and communication) on IQ (contextual and representational) of Malaysian hotels. A quantitative research design was adopted in this study. To collect the data required to analyse the study's hypothesised model, 505 questionnaires were distributed to marketing managers at Malaysian Association of Hotels (MAH) member hotels, yielding a total of 184 analysable questionnaires with a response rate of 34.44 percent. The research data were analysed using structural equation modelling with partial least squares (SEMPLS). Despite that half of the responding hotels practiced CI informally, the study found that the level of IQ resulting from CIP was high. Furthermore, the results indicate that the planning and focus, gathering, and analysis phases of CIP had a positive and significant impact on hotels' IQ, while the communication phase had a slight negative but insignificant impact on hotels' IQ. Additionally, the results show that the analysis phase is the most relevant, followed by the gathering phase, and finally the planning and focus phases phase. These findings enrich those in positions of power like owners, managers, and practitioners, as well as academicians, with greater knowledge
\end{abstract}


Keywords:

Information Quality. Competitive Intelligence Process. Hotel. Hospitality. Tourism. Malaysia

\section{Introduction}

In many countries, tourism has grown to be a significant industry (Mohammed et al., 2017; Ahn \& Kwon, 2020). The tourist industry is one of Malaysia's significant prospective growth areas in the service economy, and it is the country's second-largest source of foreign money (Sin \& Jusoh, 2019; Yadegaridehkordi et al., 2020; Ahn \& Kwon, 2020). In 2017, it generated 3.4 million employments, and it contributed 15.2\% to Malaysia's GDP in 2019. Additionally, in 2019, it received 26.10 million tourists and generated RM 86.10 billion (Tourism Malaysia, 2020). The hotel industry is one of the most promising sectors in Malaysia, where Malaysia offers a wide range of accommodation to visitors, including hotels, individual guest houses, motels, self-catering, and other types of private accommodation. Furthermore, Malaysia had 4,826 hotels offering 315,969 rooms by the end of 2019. (Tourism Malaysia, 2020). As a result, there is a need for efficient strategies to enable the Malaysian hotel industry to overcome the fierce competition (Mohammed et al., 2017; Yadegaridehkordi et al., 2020; Ahn \& Kwon, 2020).

Despite the Malaysian government's focus on tourism, which was apparent through its 2020 vision to reach 36 million tourists, figures have revealed a decline from 27.44 million in 2014 to 26.10 million in 2019 in tourist arrivals in Malaysia (Yadegaridehkordi et al., 2020; Tourism Malaysia, 2020). Furthermore, prior researches have shown that the hotel sector works in an aggressive competitive environment and environmental turbulence, in resulting a dropped in the rate of occupancy, where the occupancy rate for Malaysian hotels fell between 2014 and 2019, starting at 69.7\% in 2014 and falling to 58.8\% in 2019 (Mohammed et al., 2017; Radzi et al., 2017; Sin \& Jusoh, 2019; Yadegaridehkordi et al., 2020; Tourism Malaysia, 2020). Another issue for most hotel managers is making rational decisions in an atmosphere marked by environmental uncertainty, as well as dealing with customers of various ethnicities, cultures, and religions (Köseoglu et al., 2016; Salguero et al., 2019; Ahn \& Kwon, 2020; Köseoglu et al., 2020). As a result, in order to stay competitive in such a difficult industry, hotel managers and executives should use appropriate strategic tools, such as Competitive Intelligence (CI) that provide them with high-quality information that enables them to make rational decisions and help them to stay in the market and flourish (Yap et al., 2014; Yan-Li \& He-feng, 2016; Salguero et al., 2019; Köseoglu et al., 2020).

Information quality (IQ) has grown in importance, particularly in the age of big data (Dabrowski, 2018; Bossé \& Rogova, 2019; Mitrovic, 2020). Where the IQ is an important factor in improving decision-making quality by providing knowledge as well as interpreting and evaluating information to facilitate decision-making (Shen et al., 2017; Wamba et al., 2019; Mitrovic, 2020). This is supported by Dabrowski (2018), Saxena \& Lamest (2018), Wamba et al., (2019), Wieder and Ossimitz (2019), who discovered that IQ has a positive impact on organisational performance, and Kyoon Yoo (2014), who discovered that perceived quality has 


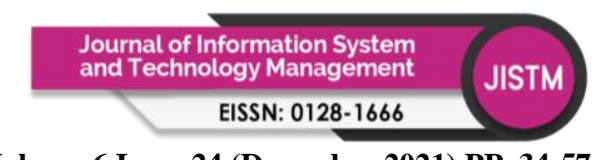

Volume 6 Issue 24 (December 2021) PP. 34-57 DOI: 10.35631/JISTM.624005

an effect on innovativeness. Similarly, Setia et al. (2013) discovered a link between Web IQ and organisational capabilities and performance. Furthermore, decision-makers use of IQ has been found to have an effect on organisational performance (Ji-fan Ren et al., 2017; Wieder \& Ossimitz, 2019; Mitrovic, 2020). Similarly, Stonier (1991) emphasised the critical roles of IQ for the economy, society, and the whole world. Indeed, identifying and managing corporate information has become an important specialized business sub-discipline. In this regard, organizations are encouraged to utilize intelligence to identify, analyse and manage information because the availability of information alone is not enough for strategic decisions (Ashrafi \& Ravasan, 2018; Wieder \& Ossimitz, 2019; Mitrovic, 2020). In this regard, previous researchers argued that the quality of the information received by decision-makers is critical to the success of any organisation. As a result, more efficient intelligent systems and practices, such as CI, are required to provide accurate and timely information, as well as to determine the level of information quality required to ensure a positive relationship between CI use and firm succusses (Wieder \& Ossimitz, 2015; Saxena \& Lamest, 2018; Dabrowski, 2018; Markovich et al., 2019; Key \& Challagalla, 2020).

Competitive intelligence (CI) systematic, targeted, timely and ethical process that focuses on collecting, synthesizing, and analysing information from both the internal and the external environment of the firm, and disseminate it to company decision-makers (Calof et al., 2018; Oraee et al., 2020; van den Berg et al., 2020; Madureira et al., 2021). Accordingly, CI's unique capability is to provide managers with accurate and useful information that leads to informed and effective decisions as well as helping organisations to be more efficient (Jaklič et al., 2018; Bossé \& Rogova, 2019; Chummun \& Singh, 2019; Markovich et al., 2019; Mitrovic, 2020; Madureira et al., 2021). Additionally, CI helps to identify future opportunities and hazards by contributing to the discovery of new possibilities (Calof, 2017; Köseoglu et al., 2019; Maritz \& du Toit, 2018; Mohamad et al., 2018; Lutz \& Bodendorf, 2020). Additionally, CI is a strategic instrument that aids in the identification of prospective opportunities and dangers (Hendar et al., 2020; Oraee et al., 2020). Companies can use CI to improve their ability to access and evaluate competitive information, allowing them to better capture market opportunities (Søilen, 2017; Hendar et al., 2020; Silva, 2021). Companies can also utilise CI to increase their ability to obtain competitor information in a competitive setting and use that information for decision-making and performance improvement (Wright et al., 2009; Hendar et al., 2020; Calof \& Sewdass, 2020; Silva, 2021). Indeed, some researchers believe that CI is like a firm's radar to sense opportunities and threats surrounding (Søilen, 2017; Collovini et al., 2020). As a result, $\mathrm{CI}$ is a valuable resource for strategic planning and other operations since it gives data on present and future rivals' activities (Hendar et al., 2020; Calof \& Sewdass, 2020; Silva, 2021). In this regard, CI has positioned itself among the top strategic practices for supporting an organization's performance and enhancing the competitive advantages of the organizations (Oraee et al., 2020; Falahat et al., 2020; Calof \& Sewdass, 2020; Vugec et al., 2020; Hanif et al., 2021; Silva, 2021). Accordingly, CI is continuously emerging as a strategic practice for hotel companies to distinguish themselves from their competitors (Yap et al., 2014; Yan-li \& He-feng, 2015; Köseoglu et al., 2016; Yan-Li \& He-feng, 2016; Köseoglu et al., 2020). In addition, according to Yan-li \& He-feng (2015), Yan-Li and He-feng (2016), and Salguero et al. (2019), the hotel industry is in a dire need of CI especially in the era of big data where the better full practice of CI will assist hotel managers to develop well informed and wiser marketing decisions by providing them with quality, timely and overall information, which can, in turn, lead to competitive advantage for hotels. 


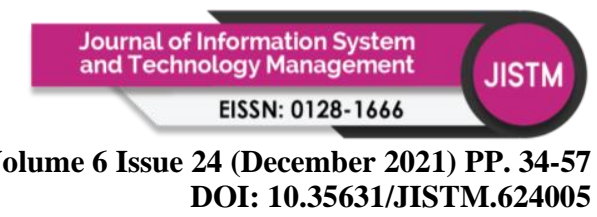

Despite the imperative role of CI for organizational survival, the field of application has varied. Some companies use CI at the tactical level, while others use it at the strategic level, and there is also a disparity in the success of implementing CI from one company to another and from one sector to another (Yan-li \& He-feng, 2015; Köseoglu et al., 2016; Søilen, 2017; Cavallo et al., 2020; Silva, 2021). However, several studies have revealed that there is a low level of awareness of CI among hotel managers (Yap et al., 2014; Köseoglu et al., 2016; Salguero et al., 2019; Köseoglu et al., 2020). Furthermore, although CI has been widely used in the service sector, the literature indicated limited research of CI within the hospitality sector (Köseoglu et al., 2016; Salguero et al., 2019; Köseoglu et al., 2020). Similarly, the impact of practicing the process of competitive intelligence (CIPs) as a multi-stage (Planning and focus, collection, analysis, and communication) on IQ has not received enough attention from academics, and there is still a lack of empirical studies in this area (Saxena \& Lamest, 2018; Wamba et al., 2019; Markovich et al., 2019; Wieder and Ossimitz, 2019; Vugec et al., 2020). Specifically, previous empirical studies which addressed CIPs in the Malaysian hotel context and tourism are still very scarce (Yap et al., 2014; Yap et al., 2018). Therefore, the use of IQ (Contextual IQ and representational IQ) to evaluate the impact of the CI process in hotel companies is crucial (Yan-li \& He-feng, 2015; Yan-Li \& He-feng, 2016; Laumer et al., 2017; Salguero et al., 2019; Köseoglu et al., 2020). Furthermore, these authors recommended that future studies should investigate CI dimensions in a variety of industries particularly the hotel industry. Thus, this study is one of the first to assess the influence of each phase of CIP phases on Malaysian hotels' IQ. Therefore, this study examines the following research questions:

$R Q 1$ : What is the level of IQ resulting from CIP in Malaysian hotels?

$R Q 2$ : Do the CIP phases (planning and focus, gathering, analysis, and communication) have an impact on IQ in Malaysian hotels?

\section{Literature Review}

\section{Competitive Intelligence Process (CIP)}

Competitive intelligence is a relatively new academic research topic, although it is an established corporate activity (Du Toit, 2015; Calof, 2017; Oraee et al., 2020; Madureira et al., 2021). According to Tao and Prescott (2000), Søilen (2017), and Oraee et al. (2020), CI predates Chinese history by approximately 5,000 years. Porter first proposed the concept of CI in academic circles in 1980, when he published a paper on competitive strategy (Oraee et al., 2020). Furthermore, the CI process appears to have expanded dramatically and is regarded as one of the most rapidly developing fields in the business domain as a result of CI involvement with various disciplines with diverse theoretical foundations such as management, economics, computer science, information science, and so on (Oraee et al., 2020; Madureira et al., 2021). Scientific associations and the professional community are also involved in this field (Søilen, 2017; Oraee et al., 2020). Despite this, Tao and Prescott (2000), Tej Adidam et al. (2012), Köseoglu et al. (2019), and Oraee et al. (2020) identified an important research gap on CI practise in emerging economies and emphasised that there is insufficient knowledge about how $\mathrm{CI}$ is conducted in these markets where the institutional framework differs significantly from that in developed economies. In general, no precise and widely accepted definition of CI is provided; however, various perspectives on CI definition can be found in the literature (Pellissier \& Nenzhelele, 2013; Oraee et al., 2020). Breakspear (2013) defines CI as two concepts: competitiveness and intelligence. The former refers to a competition between two or 


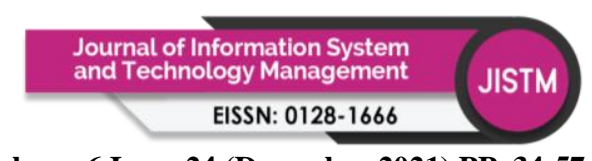

Volume 6 Issue 24 (December 2021) PP. 34-57 DOI: 10.35631/JISTM.624005

more groups, organisations, or corporations. The latter refers to a corporate capability that incorporates foresight and insights with the goal of recognising impending change, which could be positive and represent opportunities, or negative and represent threats (Breakspear, 2013). According to SCIP (2009), Yin (2018), and Oraee et al., CI can be described as a process or a product (2020). Competitive intelligence (CI) is defined by the Society of Competitive Intelligence Professionals (SCIP) as a continuous process that includes legal and ethical methods for gathering information, analysing it, and controlling its dissemination so that decision-makers can make informed decisions about marketing, $\mathrm{R} \& \mathrm{D}$, and investing tactics, as well as long-term business strategies (SCIP, 2009). Meanwhile, CI is defined as information about current and future customer, competitor, and supplier behaviour, as well as information about the government, market, and general business environment (Calof, 2017; Yin, 2018). As a result, for the purposes of this study, the concept of CI as a branch of BI was used as a process.

The competitive Intelligence Process (CIP) is a continuous and integrated process with a series of phases that must be carried out in a precise order in order to produce competitive intelligence products (Calof et al., 2018; Oraee et al., 2020). There is, however, no consensus on which phases make up the CIP. As a result, CIP has been proposed in a variety of ways, and while certain similarities exist, there are still differences in the structure of CIP, the number of stages, and the terminology for the different phases (Calof, 2017; Oraee et al., 2020; Nyberg). Despite this, earlier research (Saayman et al., 2008; Nasri, 2011; Seyyed-Amiri et al., 2017; Hanif et al., 2021) indicates to support these stages of CIP "Planning and focus, Gathering, Analysis, and Communication":

\section{Planning and Focus Phase (CIP-PF)}

CIP-PF is concerned with defining the needs of decision-makers, assigning appropriate resources, and deciding on the $\mathrm{CI}$ aim and desired outcomes. This phase is important for two reasons: first, it allows CI practitioners to focus on what is most important for end-users (decision-makers) in terms of the information needed to meet or exceed their demands and expectations; and second, it allows CI practitioners to focus on what is most important for endusers (decision-makers) in terms of the information and its quality required to meet or exceed their demands and expectations (Saayman et al., 2008; Pellissier \& Nenzhelele, 2013; SeyyedAmiri et al., 2017; Oraee et al., 2020; Hanif et al., 2021).

\section{The Gathering Phase (CIP-G)}

CIP-G is involved with finding potential sources of information and legally and ethically collecting data or information from a variety of sources, including internal and external, qualitative and quantitative, human sources, and textual sources (Saayman et al., 2008; Pellissier \& Nenzhelele, 2013; Seyyed-Amiri et al., 2017; Oraee et al., 2020; Hanif et al., 2021). It's also worth noting that gathering also requires ensuring that prospective sources and information quality are correct (Pellissier \& Nenzhelele, 2013; Oraee et al., 2020; Madureira et al., 2021; Hanif et al., 2021).

\section{The Analysis Phase (CIP-A)}

CIP-A is crucial since it is here that genuine intelligence is developed (Calof et al, 2018; Oraee et al., 2020; Hanif et al., 2021). Its main goal is to turn collected data into actionable intelligence that can be used to make tactical and strategic choices (Calof et al., 2018; Oraee et al., 2020; Hanif et al., 2021). The analysis phase evaluates the collected and relevant data and information 


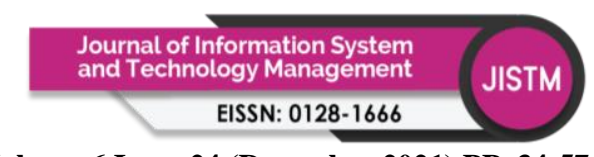

Volume 6 Issue 24 (December 2021) PP. 34-57 DOI: 10.35631/JISTM.624005

for applicability and significance, then converts the findings into actionable high-quality information (intelligence) that will improve the planning and decision-making process, ultimately leading to the development of critical strategies and improved performance (Salguero et al., 2017; Oraee et al., 2020; Hanif et al., 2021). Furthermore, according to the literature, there are a variety of analysis techniques that can be used to provide the intelligence needed to make strategic decisions, including Boston Consulting Group (BCG growth) or the share portfolio matrix, industry analysis (Porter's Five Forces Model), The General Electric Business Screen matrix, strategic group analysis, financial ratios, and value chain analysis (Nasri,2011; Pellissier \& Nenzhelele, 2013; Oraee et al., 2020; Hanif et al., 2021).

\section{The Communication Phase (CIP-C)}

CIP-C is important because it ensures that the findings of the analysis phase (intelligence process) are properly communicated to decision-makers who are authorised and responsible to act on the findings in an easily understandable format, using various channels such as e-mails, reports, seminars, short notes, and so on (Salguero et al., 2017; Calof et al, 2018; Hanif et al., 2021). Furthermore, the communication phase provides information that may be used to improve the CI process, especially between the intelligence team and decision-makers (Oraee et al., 2020; Hanif et al., 2021).

\section{Information Quality (IQ)}

IQ has become a critical issue in the era of an information society, according to Dabrowski (2018), Saxena and Lamest (2018) Markovich et al. (2019), and it is a major factor for distinguishing between usable and redundant information. Furthermore, information quality is an important competitive weapon for businesses in the twenty-first century, according to Dabrowski (2018) and Maravilhas (2018). The definition of IQ, on the other hand, is a point of contention. IQ has been described in a variety of ways in the literature; for example, Gustavsson and Jonsson (2008) defined it as a concept of "fitness for use." IQ, according to another widely recognised definition, is "knowledge that is fit for use and fulfils the purpose for which it is intended" (Laumer et al., 2017; Bossé \& Rogova, 2019). The idea of IQ can be stated in terms of outputs that are important for decision making, beneficial for business users, meet users' information criteria, and are easy to grasp, according to Gorla et al. (2010) and Bossé and Rogova (2019). They also noted the concept of IQ can be described in terms of outputs that are relevant for decision making, useful for business users, meet users' information specifications, and easy to understand (representing IS quality as value). Information should reflect the important criteria required by customers that are useful for firm performance (Marshall \& Harpe, 2009; Bossé \& Rogova, 2019; Mitrovic, 2020). Indeed, IQ refers to the ultimate and significant information or knowledge required by firms to develop strategies, and attain sustainable and competitive advantage (Visinescu et al., 2017; Wamba et al., 2019). Despite this, surprising and, even more remarkably, previous research has still failed to acknowledge the important role that IQ plays in the era of information (Dabrowski, 2018; Saxena \& Lamest, 2018; Markovich et al., 2019). Therefore, this study is one of the first studies that measure the impact of each stage of CIP in the context of hotels.

One of the most important concerns for practitioners and researchers in the field of information science is determining IQ and offering resources to improve information source selection (Arazy et al., 2017; Key \& Challagalla, 2020). Information has long been recognised as a valuable asset that enables organizations to reduce environmental risks and improve 


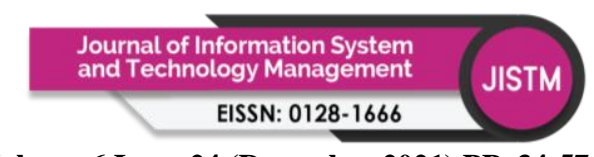

Volume 6 Issue 24 (December 2021) PP. 34-57 DOI: 10.35631/JISTM.624005

performance (Ashrafi \& Ravasan, 2018; Wieder \& Ossimitz, 2019; Key \& Challagalla, 2020). Previous research on information science has focused on the underlying properties of IQ dimensions, such as correctness, completeness, presentation, and objectivity (DeLone \& McLean, 1992; Lee et al., 2002; Arazy et al., 2017; Wieder \& Ossimitz, 2019; Bossé \& Rogova, 2019). These studies have mostly focused on the importance of IQ dimensions, with the goal of determining the best dimension to represent users' perceptions. Furthermore, according to Arazy and Kopak (2011) and Bossé \& Rogova (2019), consumers interpret different characteristics of information in different ways based on their skill and knowledge, gender, and information-seeking style. IQ is a multidimensional construct with certain features that indicate the quality and the success of business intelligence (BI) systems (Lee et al., 2002; Bossé \& Rogova, 2019). Arazy et al. (2017) and Bossé and Rogova (2019) combine these parameters into dimensions or groups that have similar traits, such as contextual, intrinsic, accessible, and representational are four high-level categories for the multidimensional IQ construct. Their methodologies included a model of measurement and analysis however they did not apply it to elaborate a dependent variable such as user satisfaction or the manifestation of workarounds (Laumer et al., 2017). The multidimensional construct was empirically characterised by Laumer et al. (2017) into two high-level categories: contextual and representational. They stated that distinguishing between representational and contextual IQ as two essential components of IQ is critical. In the context of this investigation, these two dimensions are used.

In addition, Lee et al. (2002) defined contextual IQ as "the necessity that IQ is used in the context of the activity at hand." According to the previous literature, contextual IQ encompasses the qualities of relevance, completeness, timeliness, and importance (DeLone \& McLean, 1992; Laumer et al., 2017; Bossé \& Rogova, 2019). Furthermore, Lee et al. (2002) defined representational IQ as the need to ensure correct information display for ease of interpretation and manipulation. According to Arazy and Kapak (2011), representational IQ is defined as the degree to which the information being assessed is simple to comprehend and presented in a clear, succinct, and consistent manner. Furthermore, the literature suggests that understanding, format, conciseness, readability, clarity, compatibility, and meaningfulness are all features of representational IQ (DeLone \& McLean, 1992; Laumer et al., 2017; Bossé \& Rogova, 2019). Additional features of representational IQ include the ability to be quickly updated, joined, downloaded/uploaded, modified, manipulated, aggregated, replicated, integrated, and customised (Dooley, 2015).

\section{Hypotheses Development}

\section{CIPs and Hotel's Information Quality}

Kohli and Jaworski (1990) stated that intelligence practise is critical for obtaining high-IQ and that CI as part of BI should focus on output quality. CI is a strategic instrument that gives relevant information, prevents undesirable information, makes data unique and trustworthy, and uses information strategically (Maritz \& du Toit, 2018; Mohamad et al., 2018; Salguero et al., 2019; Lutz \& Bodendorf, 2020). The core of CIP is its ability to improve and facilitate decision-making by providing managers with high-quality information that leads to more informed and efficient decisions and improved organisational performance (Jaklič et al., 2018; Bossé \& Rogova, 2019; Chummun \& Singh, 2019; Markovich et al., 2019; Madureira et al., 2021). We can utilise the CI idea interchangeably with different terminologies such as BI and market intelligence (MI), according to Köseoglu et al. (2016), Calof (2017), and Oraee et al. 


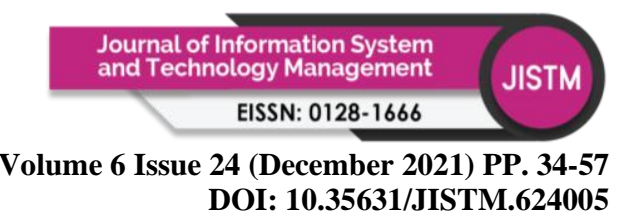

(2020). Furthermore, Markovich et al. (2019) and Vugec et al. (2020) discovered that while CI has no direct impact on firm performance, it does have an indirect impact through intermediate variables like information quality. Wieder and Ossimitz (2015), Daradkeh and Al-Dwairi (2018), Wieder and Ossimitz (2019) and Lutz and Bodendorf (2020) have all found that CI has a favourable connection with IQ. As a result, IQ is one of the most important, accurate, and easily available benefits of intelligent and analytical procedures (Watson et al., 2002; Lutz \& Bodendorf, 2020). Despite this, surprising and, even more remarkably, previous research has still failed to acknowledge the important role that IQ plays in the era of information (Dabrowski, 2018; Saxena \& Lamest, 2018; Markovich et al., 2019). Therefore, this study is one of the first studies that measure the impact of each stage of CIP in the context of hotels.

$\mathrm{CI}$ is an important strategy for the hotel industry that can be used to improve the quality of information about customers and competitors, increase guest patronage, and improve competitive advantage (Yan-li \& He-feng, 2015; Köseoglu et al., 2016; Daradkeh \& Al-Dwairi, 2018; Salguero et al., 2019; Köseoglu et al., 2020). Previous research has also discovered a link between CI and IQ. One of CI's significant achievements is its ability to focus on output quality as information quality (IQ) (Teo \& Choo, 2001; Wieder \& Ossimitz 2015; Ashrafi \& Ravasan, 2018; Torres \& Sidorova, 2019). According to Yan-li and He-feng (2015), Markovich et al. (2019), and Kumar et al. (2020), the most major value supplied by CIP is the acquisition of high-quality information for decision-making to improve the organization's performance. Quality of information, according to Jaklič et al. (2009), and Wamba et al. (2019), promotes well-informed decision-making, improves planning, and provides sustainable competitive advantage strategies. Furthermore, previous academics asserted that the quality of information gathered by decision-makers is critical to the success of any company. As a result, more efficient intelligent systems and processes, such as CIP, are required to supply accurate and timely information, as well as to establish the level of information quality required to ensure a positive association between CIP utilisation and firm performance (Shen et al., 2017; Visinescu et al., 2017; Markovich et al., 2019; Key \& Challagalla, 2020). CIP generates IQ (competitive intelligence products) through a continuous and integrated process with a set of stages according to Oraee et al. (2020) and Calof and Sewdass (2020). Therefore, we proposed the following hypotheses:

H1: The CIP's planning and focus phase influences IQ in Malaysian hotels.

H2: The CIP's gathering phase influences IQ in Malaysian hotels.

H3: The CIP's analysis phase influences IQ in Malaysian hotels.

H4: The CIP's communication phase influences IQ in Malaysian hotels.

According to the theoretical framework and prior hypotheses, the conceptual framework will be depicted as in Fig.1. 


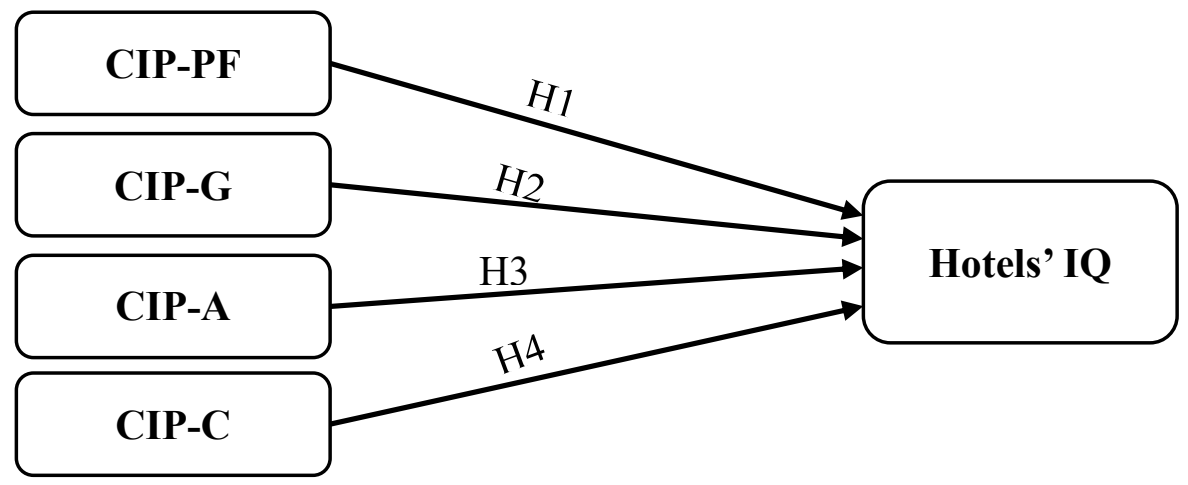

Figure1: The Conceptual Framework

\section{Methodology}

The main goal of this research is to define the level of IQ in Malaysian hotels, as well as investigating the influence of each phase of CIP on the contextual and representational IQ of Malaysian hotels. To achieve these goals, we employed a quantitative approach to collect data from Malaysian hotels' marketing managers. There is empirical evidence from previous studies where researchers in previous studies used hotel marketing managers as the main respondents e.g., Yap et al. (2014), Yan-li \& He-feng (2015), Yan-Li and He-feng (2016), Köseoglu et al. (2016) and Köseoglu et al. (2019), moreover, Yap et al. (2014), Köseoglu et al. (2019) and Markovich et al. (2019) noted that CI unit is located within the marketing management. Thus, it is anticipated that the marketing managers will be accurate to fully answer virtually all questions. The population in this study comprised hotels in Malaysia with 3- to 5-star ratings, which totalled 535 hotels in December 2018, according to the Malaysian Association of Hotels (MAH, 2018). Yap et al. (2014) and Köseoglu et al. (2016) argued that these types of hotels are suitable for investigating CIP since they are superior to one-star and two-star hotels in terms of management organisation, information handling, and institutionalisation. Because of the study population's small size, Zikmund (2003) and Zikmund et al. (2013) advised that if the population has a small population size, the researcher should investigate the entire population rather than selecting a sample size. Thus, we used a survey of the total population, which included $535-3$ to 5-star hotels based on the MAH membership database. Since Malaysian hotels are located in various and spaced areas, data was gathered using a questionnaire over a four-month period from November 2019 to February 2020. After excluding the 30 hotels that were used in the pilot study, the questionnaires were distributed via email to the marketing managers of 505 hotels. Due to the low recovery rate of email surveys, researchers visited hotels in Northern Malaysia (Pulau Pinang, Kedah, and Perlis), as well as the majority of hotels in Kuala Lumpur, Selangor, and Malacca, and the total number of questionnaires recovered is 192. After checking for damaged questionnaires and outlier data, the final review of the questionnaires received yielded 184 questionnaires (36.44 percent) that were appropriate for data analysis. In terms of the profile of respondents, the male respondents made up 45.1 percent of the total, while female respondents made up 54.9 percent. The majority of the responders were between the ages of 36 and 45 with $44.6 \%$. All respondents held a managerial role, with the majority (91.3\%) holding the marketing manager job, followed by the sales manager position (7.6\%). As a result, all respondents were regarded qualified to answer questions on the hotel's IQ and CIP practice. They were also aware of CI practices, as the majority of 


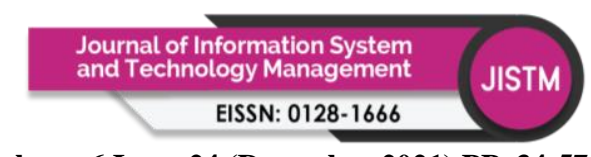

Volume 6 Issue 24 (December 2021) PP. 34-57 DOI: 10.35631/JISTM.624005

respondents had worked in this hotel for 4-9 years and had a percentage of 68 percent, while the majority of the respondents had ten years and more of experience working in the hotel sector, with a percentage of 67.4 percent. In terms of hotel profile, 31.5 percent of hotels were classified as "three-star," 40.2 percent as "four-star," and the rest as "five-star". The majority of the hotels, on the other hand, were classified as city hotels (78.8 percent). 75 percent of hotels have been open for more than ten years, making them mature establishments. The majority of these hotels had over 300 rooms. In addition, Selangor had the highest percentage of people who responded to the survey, with 26.6 percent.

\section{Measures}

The operationalization of the IQ measurement in this study was based on fifteen items distributed across two dimensions (contextual and representational IQ) as a second-order drawn from Lee et al. (2002), DeLone \& McLean (2003), and Petter et al. (2013), and revised by Laumer et al (2017). The measuring items were tailored to the hotel's CIP. Furthermore, CIP has been measured by 18 items divided into four sub-dimensions are (planning and focus (CIPPF) have 4 items, gathering (CIP-G) has 4 items, analysis (CIP-A) has 6 items, and communication (CIP-C) has 4 items). Previous research has found that subjective assessments of CIPs and IQ in hotels can be useful. The five constructs were assessed using a "5-point Likert scale, with 1 indicating "strongly disagree" and 5 indicating "strongly agree" for the statements proposed". After that, respondents were asked to give their opinions on CIPs and IQ in their hotels depending on the previous three years.

\section{Results}

To analyse the results of this study and to achieve its objectives, two statistical packages were used, namely, the statistical package for social sciences "SPSS" and "structural equation modelling for partial least squares". Where the first package was used to measure the level of IQ resulting from CI in Malaysian hotels. While we used SEM-PLS to evaluate the measurement model and structural model in order to report key findings on the "measurement model" and the "structural model" which include constructing, the validity of discriminant and convergent, the analysis of reliability, the predictive importance for the model, and impact size. The path modelling of PLS had successfully expanded use in several research fields, like, strategic-management, marketing, information-system, social psychology, and management science than others (Hair et al., 2019). According to Hair et al. (2019) PLS-SEM considers a suitable and sturdy method for numerous situations observed in the research of social sciences.

\section{The Level of IQ in Malaysian Hotels}

In order to measure the level of IQ (Contextual (CIQ) and Representational (RIQ) in Malaysian hotels, descriptive statistics were calculated that include mean and deviations' standards. As explained above, structures were measured in the current study using the "5-point Likert scale". So, we used three classes depending on Noor and Kumar (2014), to illustrate the level of IQ in Malaysian hotels, namely: the low values which are less than 2.33 ("4/3 + lowest-value (1)"), the high values which are higher than 3.67 (the highest-value "(5) - 4/3)" and the moderate values which are located among high and low values.

In addition, the overall mean for all items of the contextual IQ (CIQ) ranged between, 3.88 to 4.103, which indicated that all items of CIQ get the high level of mean values, as well the total mean value of CIQ had a high level of mean with 3.98 value, as displayed in table 1 . 
Volume 6 Issue 24 (December 2021) PP. 34-57 DOI: 10.35631/JISTM.624005

Additionally, the overall mean for all items of the representational IQ (RIQ) ranged between, 3.527 to 4.038 , which indicated that most items of RIQ get the high level of mean values, as well the total mean value of RIQ had a high level of mean with 4.068 value, as displayed in table 1. In specific, all dimensions of IQ (CIQ and RIQ) have a high level of the means 3.98 and 4.068 with moderate standard deviation 0.644 and 0.752 respectively, this reflects the interest of marketing managers in Malaysian hotels on the importance of dimensions of IQ and CIP that generated IQ. The high level of mean values reflects that the level of IQ is high in Malaysian hotels. see Table 1.

Table 1: Descriptive Statistics for The Level of Hotels' IQ (N=184)

\begin{tabular}{|c|c|c|c|c|}
\hline \multirow{4}{*}{ Dimension } & Item & Mean & $\begin{array}{c}\text { Std. } \\
\text { Deviation }\end{array}$ & $\begin{array}{c}\text { Level of } \\
\text { IQ }\end{array}$ \\
\hline \multirow{5}{*}{ Contextual IQ } & CIQ1 & 3.880 & 0.787 & High \\
\cline { 2 - 5 } & CIQ2 & 3.891 & 0.760 & High \\
\cline { 2 - 5 } & CIQ3 & 3.995 & 0.728 & High \\
\cline { 2 - 5 } & CIQ4 & 4.103 & 0.674 & High \\
\cline { 2 - 5 } & CIQ5 & 4.087 & 0.696 & High \\
\cline { 2 - 5 } & CIQ6 & 3.935 & 0.807 & High \\
\cline { 2 - 5 } & CIQ7 & 3.957 & 0.855 & High \\
\cline { 2 - 5 } & CIQ8 & 3.924 & 0.772 & High \\
\cline { 2 - 5 } & CIQ9 & 4.049 & 0.647 & High \\
\cline { 2 - 5 } & Total & 3.980 & 0.644 & High \\
\hline \multirow{5}{*}{$\begin{array}{c}\text { Representational } \\
\text { IQ }\end{array}$} & RIQ1 & 4.038 & 0.749 & High \\
\cline { 2 - 5 } & RIQ2 & 3.984 & 0.902 & High \\
\cline { 2 - 5 } & RIQ3 & 4.027 & 0.871 & High \\
\cline { 2 - 5 } & RIQ4 & 3.576 & 0.764 & Moderate \\
\cline { 2 - 5 } & RIQ5 & 3.527 & 0.669 & Moderate \\
\cline { 2 - 5 } & RIQ6 & 3.755 & 0.775 & High \\
\cline { 2 - 5 } & Total & 4.068 & 0.752 & High \\
\hline
\end{tabular}

\section{The Resulting of The Measurement Model}

The measuring model was evaluated using Hair et al. (2019) guidelines, which looked at construct, convergent, and discriminant validity. Construct validity refers to the use of the results acquired by using the measure and applicable theories while creating a test (Sekaran \& Bougie, 2016). This concept can be realised by looking at the item's factor loading in the content validity of the measurement model (Chin, 2010; Hair et al., 2014). In this circumstance, all items should be significantly higher on their hypothesised factor than on other factors (Chin, 2010). As a result, certain items are deleted if other factors load higher than their respective build (Hair et al., 2014). This paper uses factor loading as a primary factor, with a cut-off criterion of 0.70 (Hair et al., 2019). The loadings for all items were larger than 0.70, as shown in Table 2. Therefore, this finding confirms the content validity of the measurement model. As a result, this conclusion supports the measurement model's content validity. 
Table 2: Loadings and Cross-Loadings

\begin{tabular}{|c|c|c|c|c|c|c|}
\hline Item & $\begin{array}{c}\text { CIP- } \\
\text { PF }\end{array}$ & CIP-G & CIP-A & CIP-C & $\begin{array}{c}\text { IQ- } \\
\text { CIQ }\end{array}$ & $\begin{array}{c}\text { IQ- } \\
\text { RIQ }\end{array}$ \\
\hline CIP_PF1 & $\mathbf{0 . 8 3}$ & 0.73 & 0.69 & 0.62 & 0.72 & 0.70 \\
\hline CIP_PF2 & $\mathbf{0 . 9 0}$ & 0.71 & 0.69 & 0.64 & 0.65 & 0.61 \\
\hline CIP_PF3 & $\mathbf{0 . 8 4}$ & 0.72 & 0.62 & 0.52 & 0.67 & 0.67 \\
\hline CIP_PF4 & $\mathbf{0 . 8 1}$ & 0.80 & 0.77 & 0.69 & 0.67 & 0.66 \\
\hline CIP_G1 & 0.78 & $\mathbf{0 . 8 8}$ & 0.79 & 0.76 & 0.77 & 0.75 \\
\hline CIP_G2 & 0.71 & $\mathbf{0 . 8 2}$ & 0.66 & 0.53 & 0.66 & 0.65 \\
\hline CIP_G3 & 0.64 & $\mathbf{0 . 8 3}$ & 0.68 & 0.63 & 0.67 & 0.60 \\
\hline CIP_G4 & 0.80 & $\mathbf{0 . 8 2}$ & 0.81 & 0.77 & 0.67 & 0.67 \\
\hline CIP_A1 & 0.74 & 0.80 & $\mathbf{0 . 8 7}$ & 0.73 & 0.74 & 0.79 \\
\hline CIP_A2 & 0.75 & 0.80 & $\mathbf{0 . 8 9}$ & 0.73 & 0.79 & 0.78 \\
\hline CIP_A3 & 0.74 & 0.81 & $\mathbf{0 . 8 8}$ & 0.74 & 0.70 & 0.71 \\
\hline CIP_A4 & 0.56 & 0.60 & $\mathbf{0 . 7 2}$ & 0.57 & 0.61 & 0.53 \\
\hline CIP_A5 & 0.55 & 0.57 & $\mathbf{0 . 7 4}$ & 0.68 & 0.50 & 0.48 \\
\hline CIP_A6 & 0.61 & 0.67 & $\mathbf{0 . 7 5}$ & 0.78 & 0.54 & 0.55 \\
\hline CIP_C1 & 0.57 & 0.70 & 0.72 & $\mathbf{0 . 8 6}$ & 0.57 & 0.52 \\
\hline CIP_C2 & 0.62 & 0.72 & 0.76 & $\mathbf{0 . 9 3}$ & 0.57 & 0.57 \\
\hline CIP_C3 & 0.45 & 0.40 & 0.49 & $\mathbf{0 . 6 1}$ & 0.32 & 0.39 \\
\hline CIP_C4 & 0.76 & 0.81 & 0.86 & $\mathbf{0 . 9 2}$ & 0.72 & 0.72 \\
\hline CIQ1 & 0.66 & 0.61 & 0.59 & 0.46 & $\mathbf{0 . 8 4}$ & 0.74 \\
\hline CIQ2 & 0.70 & 0.68 & 0.69 & 0.55 & $\mathbf{0 . 8 6}$ & 0.80 \\
\hline CIQ3 & 0.75 & 0.82 & 0.80 & 0.71 & $\mathbf{0 . 8 8}$ & 0.81 \\
\hline CIQ4 & 0.62 & 0.67 & 0.65 & 0.58 & $\mathbf{0 . 8 6}$ & 0.69 \\
\hline CIQ5 & 0.67 & 0.74 & 0.72 & 0.61 & $\mathbf{0 . 8 6}$ & 0.73 \\
\hline CIQ6 & 0.74 & 0.74 & 0.74 & 0.66 & $\mathbf{0 . 8 7}$ & 0.79 \\
\hline CIQ7 & 0.74 & 0.77 & 0.74 & 0.62 & $\mathbf{0 . 8 4}$ & 0.85 \\
\hline CIQ8 & 0.72 & 0.68 & 0.65 & 0.49 & $\mathbf{0 . 9 0}$ & 0.82 \\
\hline CIQ9 & 0.63 & 0.73 & 0.68 & 0.56 & $\mathbf{0 . 8 4}$ & 0.74 \\
\hline RIQ1 & 0.74 & 0.75 & 0.73 & 0.64 & 0.82 & $\mathbf{0 . 8 7}$ \\
\hline RIQ2 & 0.71 & 0.77 & 0.78 & 0.69 & 0.78 & $\mathbf{0 . 8 6}$ \\
\hline RIQ3 & 0.71 & 0.72 & 0.75 & 0.63 & 0.84 & $\mathbf{0 . 9 1}$ \\
\hline RIQ4 & 0.61 & 0.61 & 0.58 & 0.49 & 0.68 & $\mathbf{0 . 7 9}$ \\
\hline RIQ5 & 0.48 & 0.51 & 0.51 & 0.42 & 0.59 & $\mathbf{0 . 7 2}$ \\
\hline RIQ6 & 0.52 & 0.48 & 0.50 & 0.31 & 0.61 & $\mathbf{0 . 6 6}$ \\
\hline
\end{tabular}

The construct being measured can be estimated using factor loadings, composite reliability (CR), and the extracted average variance (AVE). The recommended loading is set at 0.70; CR must be greater than 0.70 , and AVE should be greater than the generally accepted cut-off points of 0.50. Accordingly, there were 2 loading items deleted because it was less than 0.70 are 
Volume 6 Issue 24 (December 2021) PP. 34-57 DOI: 10.35631/JISTM.624005

(CIP_C3 and RIQ6). Using item loadings, the item loading for the hypothesized factor was found to be significantly higher than the other components (Chin, 2010). Furthermore, CR findings were higher than outcomes that were over 0.70. The AVE indicates that the latent variable was greater than 0.50 (Hair et al., 2019). The findings in Table 3 are higher than predicted levels, thereby validating the convergent validity of the measuring model.

Table 3: Load Factor and Convergent Validity Findings

\begin{tabular}{|c|c|c|c|c|}
\hline $\begin{array}{c}\text { Model } \\
\text { Construct }\end{array}$ & $\begin{array}{l}\text { Measurement } \\
\text { Item }\end{array}$ & Loading & $\begin{array}{c}\text { Composite } \\
\text { Reliability } \\
\text { (CR) }\end{array}$ & $\begin{array}{c}\text { Average } \\
\text { Variance } \\
\text { Extracted } \\
\text { (AVE) }\end{array}$ \\
\hline \multirow{4}{*}{$\begin{array}{l}\text { Planning and } \\
\text { Focus (CIP-PF) }\end{array}$} & CIP_PF1 & 0.830 & \multirow{4}{*}{0.907} & \multirow{4}{*}{0.711} \\
\hline & CIP_PF2 & 0.895 & & \\
\hline & CIP_PF3 & 0.835 & & \\
\hline & CIP_PF4 & 0.809 & & \\
\hline \multirow{3}{*}{$\begin{array}{l}\text { Gathering (CIP- } \\
\text { G) }\end{array}$} & CIP_G1 & 0.870 & \multirow{3}{*}{0.897} & \multirow{3}{*}{0.745} \\
\hline & CIP_G2 & 0.841 & & \\
\hline & CIP_G3 & 0.877 & & \\
\hline \multirow{4}{*}{ Analysis (CIP-A) } & CIP_A1 & 0.876 & \multirow{5}{*}{0.916} & \multirow{5}{*}{0.687} \\
\hline & CIP_A2 & 0.904 & & \\
\hline & CIP_A3 & 0.884 & & \\
\hline & CIP_A4 & 0.735 & & \\
\hline \multirow{5}{*}{$\begin{array}{l}\text { Communication } \\
\text { (CIP-C) }\end{array}$} & CIP_A5 & 0.728 & & \\
\hline & CIP_C1 & 0.896 & \multirow{3}{*}{0.939} & \multirow{3}{*}{0.838} \\
\hline & CIP_C2 & 0.930 & & \\
\hline & CIP_C4 & 0.919 & & \\
\hline & CIQ1 & 0.887 & \multirow{6}{*}{0.954} & \multirow{6}{*}{0.775} \\
\hline \multirow{4}{*}{ Contextual IQ } & CIQ2 & 0.889 & & \\
\hline & CIQ3 & 0.911 & & \\
\hline & CIQ4 & 0.898 & & \\
\hline & CIQ5 & 0.899 & & \\
\hline \multirow{6}{*}{$\begin{array}{c}\text { Representational } \\
\text { IQ }\end{array}$} & CIQ9 & 0.793 & & \\
\hline & RIQ1 & 0.890 & \multirow{5}{*}{0.923} & \multirow{5}{*}{0.708} \\
\hline & RIQ2 & 0.894 & & \\
\hline & RIQ3 & 0.913 & & \\
\hline & RIQ4 & 0.773 & & \\
\hline & RIQ5 & 0.721 & & \\
\hline
\end{tabular}

After the convergent validity was confirmed, we ran the Fornell and Larcker (1981) technique to examine the discriminant validity. To what extent is a group of items used to estimate only one construct, and to what extent is the separate estimation of this construct accomplished in the process (Hair et al., 2014). The correlation between the latent constructs will need to be greater than the square root of the AVE of each latent construct to successfully implement this 
Volume 6 Issue 24 (December 2021) PP. 34-57 DOI: 10.35631/JISTM.624005

approach (Hair et al., 2014; Fornell and Larcker, 1981). Accordingly, there were 5 items deleted that are (CIP-A6, CIP-G4, CIQ6, CIQ7, and CIQ8) in order to achieve the condition of Fornell and Larcker (1981). It can be concluded that discriminant validity is fully established because the square root of the AVE values exceeded in their own rows and columns. Table 4. displays the findings, and fig 2 . displays the measurement model.

\begin{tabular}{ccccccc} 
Table 4: Results of Discriminant Validity by "Fornell-Larcker Criterion" \\
\hline Construct & CIP-A & CIP-C & CIP-G & $\begin{array}{c}\text { CIP- } \\
\text { PF }\end{array}$ & $\begin{array}{c}\text { IQ- } \\
\text { CIQ }\end{array}$ & $\begin{array}{c}\text { IQ- } \\
\text { RIQ }\end{array}$ \\
\hline CIP-A & $\mathbf{0 . 8 3 5}$ & & & & & \\
CIP-C & 0.827 & $\mathbf{0 . 9 1 5}$ & & & & \\
CIP-G & 0.825 & 0.764 & $\mathbf{0 . 8 6 3}$ & & & \\
CIP-PF & 0.819 & 0.719 & 0.826 & $\mathbf{0 . 8 4 3}$ & & \\
IQ-CIQ & 0.791 & 0.677 & 0.788 & 0.765 & $\mathbf{0 . 8 8 0}$ & \\
IQ-RIQ & 0.807 & 0.685 & 0.774 & 0.778 & 0.842 & $\mathbf{0 . 8 5 0}$ \\
\hline
\end{tabular}

According to the findings, the recommended conceptualization of CIP-PF, CIP-G, CIP-A, and CIP-C of CIP as reflecting first-order structures was supported. This methodology is in agreement with prior research that has combined ECIP-PF, CIP-G, CIP-A, and CIP-C to create a unified approach (Saayman et al., 2008; Seyyed-Amiri et al., 2017; Hanif et al., 2021). To identify and explain the whole IQ of firms, the two dimensions of the IQ construct (as secondorder structures) were utilized (contextual and representational IQ) used in this study based on Laumer et al (2017). This research seeks to learn more about the correlation between CIP-PF, CIP-G, CIP-A, and CIP-C so that we can enhance our comprehension of how they are related to other variables.



Figure 2: Measurement Model and Path-Coefficient Results

\section{Structure-mode Valuation}

Once the model's validity and reliability had been confirmed, the hypothesized link was investigated using Smart-PLS 3.3.3. Where hypothesis H1, H2, and H3, were accepted, while Copyright $\odot$ GLOBAL ACADEMIC EXCELLENCE (M) SDN BHD - All rights reserved 


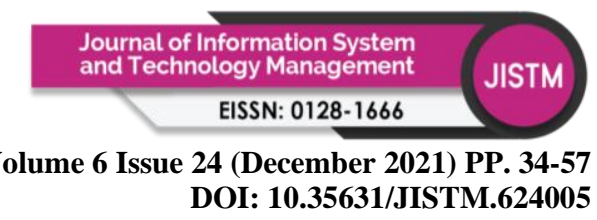

the hypothesis $\mathrm{H} 4$ was rejected, Figures $2 \& 3$, and Table 5 illustrate the results. Hair et al. (2014) noted that the important criterion for the structural model evaluation is R2, as the predictive PLS-SEM approach tries to illuminate the variance of the endogenous latent variables. So, R2, which is one of the primary objectives, should be placed in a high position. They also considered the R2 value of $0.75,0.50$, and 0.25 , and arrived at the conclusion that these values were "high, moderate, and weak", respectively. In our study, R2 obtained a value of 0.76 using the PLS algorithm, and this value considers a high level. Figure 2 shows that the CIP-PF, CIP-G, CIP-A, and CIP-C phases of CIP account for $76 \%$ of the variation in the hotel's IQ, which is in the high range. Additionally, the effect size for the latent factors on the dependent variable was evaluated using $\mathrm{f} 2$ analysis, which is a complement to R2 (Chin, 2010). According to Cohen (2013), the effect sizes (big, medium, and small) for the predictive variables are represented by f2 values of $(0.35,0.15$, and 0.02). As indicated in Table 6, CIPA has a moderate effect size (0.147) and CIP-PF and CIP-G have small impacts (0.06 and 0.09) respectively, while the CIP-C has a very small impact size (0.002). using the blindfolding approach, the model was also assessed to see if it was of a high enough quality (Henseler et al., 2015). The Stone-Geisser test can be used to simulate soft modelling comparable to hand in glove, says Valerie (2012). "This test is computed through the formula Q2=1 - sum of squares of prediction errors (SSE)/sum of squares of observations (SSO)". When blindfolding is employed, the value of Q2 is derived by counting the number of cases in the data instead of the given omissions distance. If the value of Q2 is not a multiple of the given omissions distance, then the blindfolding method provides inaccurate values, and values from 5 to 10 should be used (Hair et al., 2014). Since this research utilised 7 as the value of $d$ to represent the crossvalidated redundancy methods for each dependent variable, the current research selected 7 as the value of d. According to Hair et al. (2014), if the cross-redundancy value is larger than zero, the model has predictive value; otherwise, one cannot make any conclusions about the predictive relevance of the model. The cross-validated redundancy of hotels' performance was 0.515 , as shown in Table 7 . Thus, it was concluded that the model's prediction quality is satisfactory.

Additionally, the effect size for the latent factors on the dependent variable was evaluated using $\mathrm{f}^{2}$ analysis, which is a complement to $\mathrm{R}^{2}$ (Chin, 2010). According to Cohen (2013), the effect sizes (big, medium, and small) for the predictive variables are represented by $\mathrm{f}^{2}$ values of $(0.35$, 0.15, and 0.02). As indicated in Table 6, CIP-A has a medium effect size (0.15), and CIP-PF and CIP-G have tiny effect sizes (0.060 and 0.091), respectively on hotel performance. While, CIP-C has a very small effect size (0.002) on hotel performance.

Table 5: Hypothesis-Testing Results

\begin{tabular}{cccccc}
\hline Hypotheses & $\begin{array}{c}\text { Path } \\
\text { Coefficient }\end{array}$ & $\begin{array}{c}\text { Standard } \\
\text { error }\end{array}$ & $\begin{array}{c}\text { T } \\
\text { Statistics }\end{array}$ & $\begin{array}{c}\text { P- } \\
\text { Values }\end{array}$ & Results \\
\hline CIP-PF -> HP & 0.236 & 0.095 & 2.482 & 0.013 & Supported \\
CIP-G -> HP & 0.303 & 0.080 & 3.779 & 0.000 & Supported \\
CIP-A -> HP & 0.425 & 0.087 & 4.880 & 0.000 & Supported \\
CIP-C -> HP & -0.043 & 0.089 & 0.485 & 0.628 & Not Supported \\
\hline
\end{tabular}

Note: $* * *: p<0.01 ; * *: p<0.05 ; *: p<0.1$. 
Volume 6 Issue 24 (December 2021) PP. 34-57

Table 6: Effect Size $\left(\mathbf{F}^{2}\right)$

\begin{tabular}{cccc}
\hline Construct & $\mathbf{R}^{\mathbf{2}}$ & $\mathbf{F}^{\mathbf{2}}$ & Effect \\
\hline IQ & 0.759 & & \\
\hline CIP-PF & -- & 0.060 & Small effect \\
CIP-G & -- & 0.091 & Small effect \\
CIP-A & -- & 0.147 & Medium effect \\
CIP-C & -- & 0.002 & Very Small effect \\
\hline
\end{tabular}

Table 7: Model's Prediction Relevance

\begin{tabular}{cccc}
\hline Total & SSO & SSE & $\begin{array}{c}\mathbf{Q}^{\mathbf{2}}(\mathbf{= 1 -} \\
\text { SSE/SSO) }\end{array}$ \\
\hline Hotel's IQ & 2024 & 981.801 & 0.515 \\
\hline
\end{tabular}

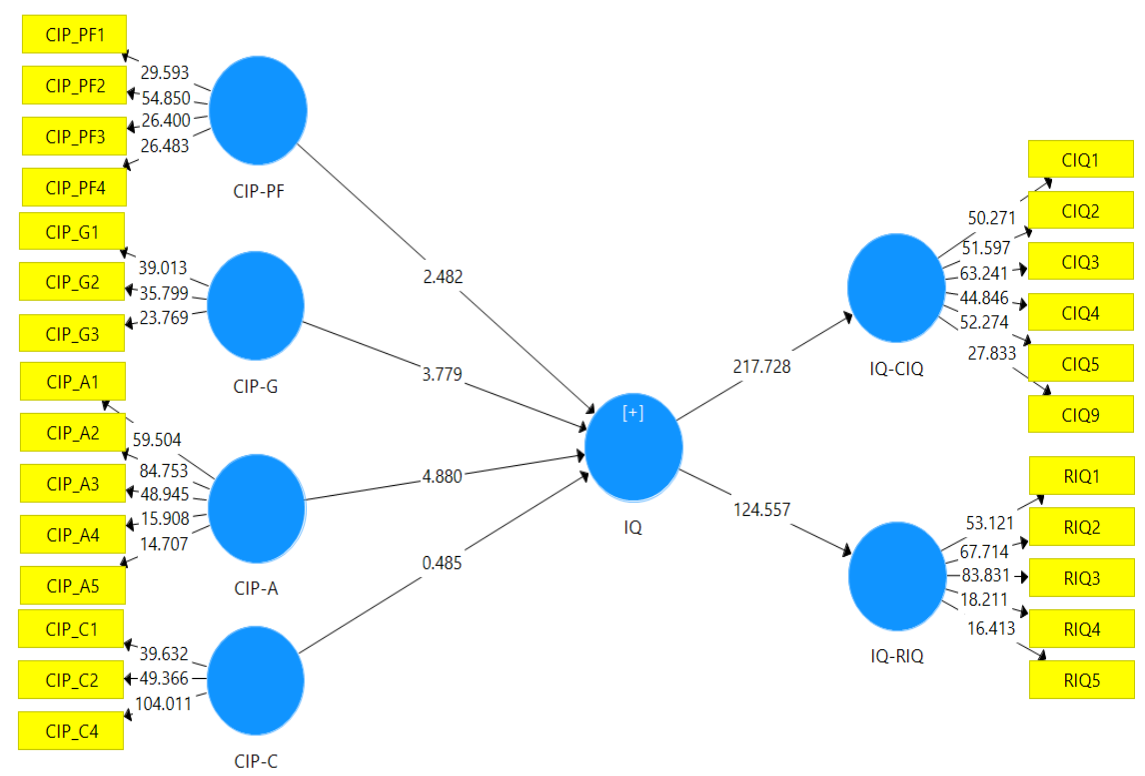

Figure 3: Hypothesis-Testing Results

\section{Discussion and Implications}

The hospitality industry is in desperate need of CI, particularly in the age of big data, where better CI practises would assist hotel managers in making better marketing decisions based on the quality of information resulting from CIP, resulting in competitive advantage (Yan-li \& He-feng, 2015; Yan-Li \& He-feng, 2016; Salguero et al., 2019). As a result, the current study sought to ascertain the level of IQ in hotels in an emerging economy such as Malaysia. Furthermore, the study seeks to determine the impact of each phase of CIP on hotels' IQ. To achieve the first goal, descriptive statistics were used, as it was discovered that, the level of IQ in terms of two dimensions (contextual and representational IQ) operation in Malaysian hotels, was high, with the arithmetic mean values for two dimensions reaching (3.980 and 4.068) respectively, and all these values are considered high based on Noor and Kumar (2014). This demonstrates that marketing managers in Malaysian hotels have a high interest in all properties of IQ resulting from CIP phases. Although marketing managers have a high interest in all phases of CIP, the CI practice in Malaysian hotels is still in its infancy and requires the attention of hotel executives to encourage the establishment of formal CI practice units. 


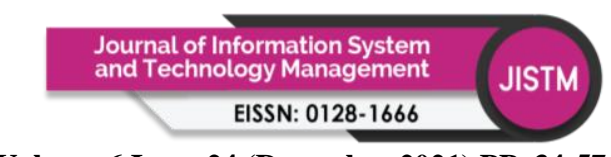

Volume 6 Issue 24 (December 2021) PP. 34-57 DOI: 10.35631/JISTM.624005

The second objective of this study is to examine the effect of CIP phases (planning and focus (CIP-PF), gathering (CIP-G), analysis (CIP-A), and communication (CIP-C)) on IQ at Malaysian hotels, which is the important phases of CIP practices (Saayman et al., 2008; Tej Adidam et al., 2012; Seyyed-Amiri et al., 2017; Hanif et al., 2021). The empirical result reveals that the CIP-PF has an impact on hotels' IQ $(\beta=0.236, \mathrm{t}=2.482, \mathrm{p}<0.05)$, as shown in Table 5. As a result, $\mathrm{H} 1$ is acceptable. This conclusion is since hotels that practice planning and focus as a phase of CIP are defining decision-makers' needs, allocating appropriate resources, and deciding on the CIP's purpose and desired outcomes. This phase is crucial for two reasons: first, it is essential to determine the required resources for the CI function, and second, it allows CI practitioners to focus on what is most relevant to end-users (Saayman et al., 2008; SeyyedAmiri et al., 2017; Oraee et al., 2020). As a result, hotels that use CIP-PF achieve high IQ.

The second part of the second objective of this study is to examine the effect of the gathering phase (CIP-G) on IQ at Malaysian hotels, which is one of the important phases of CIP practices (Tej Adidam et al., 2012; Seyyed-Amiri et al., 2017; Hanif et al., 2021). The empirical result reveals that the CIP-G has an impact on hotels' IQ $(\beta=0.303, t=3.779, p<0.001)$, as shown in Table 5. As a result, $\mathrm{H} 2$ is acceptable. This conclusion is based on the fact that hotels that practise gathering (CIP-G) phase of CIP is concerned with identifying potential sources of information and collecting data or information legally and ethically by utilising various sources, including internal and external, qualitative and quantitative, human sources, and textual, and It is also important to note that collection also entails ensuring that the potential sources and information are accurate (Saayman et al., 2008; Nasri, 2011; Seyyed-Amiri et al., 2017; Oraee et al., 2020). As a result, hotels that use the CIP-G phase achieve high IQ results.

The third part of the second objective of the study is to examine the effect of the analysis (CIPA) phase on IQ at Malaysian hotels, which is one of the important phases of CIP practices, because in this process that actual intelligence is formed (Saayman et al., 2008; Pellissier \& Nenzhelele, 2013; Calof, et. al, 2018). The empirical result reveals that the CIP-A phase has an impact on hotels' IQ $(\beta=0.425, \mathrm{t}=4.880, \mathrm{p}<0.001)$, as shown in Table 5. As a result, H3 is acceptable. This conclusion is based on the fact that hotels that practise the analysis phase (CIPA) of CIP concerned with the collected and relevant data and information for applicability and significance, then transform the results into actionable intelligence (IQ) that will improve the planning and decision-making process, ultimately leading to the development of essential strategies and improve performance (Bose, 2008; Salguero et al., 2017; Oraee et al., 2020). As a result, hotels that use CIP-A phase achieve high IQ.

The fourth part of the second objective of the study is to examine the effect of the communication phase (CIP-C) on IQ at Malaysian hotels, which is one of the important phases of CIP practice because it ensures that the findings of the analysis phase (intelligence process) are properly communicated to decision-makers who are authorised and responsible to act on the findings in a format that is easily understood, using various channels such as e-mails, reports, seminars, short notes, and so on (Saayman et al., 2008; Pellissier \& Nenzhelele, 2013; Calof, et. al, 2018). The empirical result reveals that the CIP-C phase has a slightly negative effect on hotel performance, but it is not significant $(\beta=-0.043, t=0.485, p>0.1)$, as shown in Table 5. As a result, $\mathrm{H} 4$ is unacceptable. In this case, the researchers have concluded that this outcome can be attributed to the fact that many of the hotels surveyed were practicing CIP informally. Therefore, hotels should strive to establish a formal CI unit, and train CI staff in 


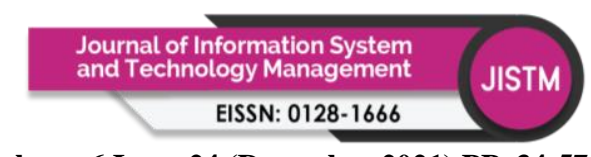

Volume 6 Issue 24 (December 2021) PP. 34-57 DOI: 10.35631/JISTM.624005

communication tools to communicate the results of the CIP to decision-makers according to their needs.

In general, the results of this study proved that all phases of CIP affect the IQ of hotels by $76 \%$, that is, the CIP-PF, CIP-G, CIP-A, and CIP-C approaches account for $76 \%$ of the variation in hotels' IQ, which is in the high range. This result is in line with the previous studies examining the impact of BI on IQ, such as Teo and Choo (2001), Popovič et al. (2012), Visinescu et al. (2017), and Shen et al., (2017). Although this result confirms the significant effect of CIP on firms' performance, there is limited research in the hotel sector such as Yan-Li and He-feng (2015) and Köseoglu et al. (2020).

\section{Conclusion and Limitations}

This study is one of the first studies that look at the effect of practice (CIP-PF, CIP-G, CIP-A, and CIP-C) on IQ in Malaysian hotels. The researchers also conducted an additional investigation about the level of IQ resulting from CIP in Malaysian hotels. The findings from the study showed that the CIP-PF, CIP-G, and CIP-A phases were strongly linked to hotels' IQ. Additional evidence shows that the analysis phase (CIP-A) is the most relevant, followed by the gathering phase (CIP-G), and finally the planning and focus phases (CIP-PF). While the communication phase (CIP-C) does not have a significant impact on hotels' performance. Moreover, the results showed that although half of the Malaysian hotels were practicing CI informally, the level of IQ resulting from CIP practice was at a high level for all dimensions (contextual and representational) of IQ. These findings have major implications for understanding how to improve the IQ in hotels. The observed difference in the shift from survival mode to hotels' growth is most clearly demonstrated by a combination of the three processes that generate the high IQ.

This study had limitations, such as the difficulty of getting all hotels in every Malaysian state, as well as the impact of the Corona pandemic, which prevented researchers from gathering further information. In addition, this research looked into the relationship between the hotels' IQ and the various CIP phases in Malaysia (CIP-PF, CIP-G, CIP-A, and CIP-C). This permits future research to focus on new aspects of CI, such as competitive intelligence context, while also increasing the response rate. The available study is limited to the hospitality business, which is the second problem. Future research should consequently focus on Malaysia's other industries. The fact that this investigation is taking place in Malaysia is the third factor to consider. Future studies will be able to reproduce the findings in different countries in order to generalise the findings.

\section{References}

Ahn, J., \& Kwon, J. (2020). Green hotel brands in Malaysia: perceived value, cost, anticipated emotion, and revisit intention. Current Issues in Tourism, 23(12), 1559-1574.

Arazy, O., \& Kopak, R. (2011). On the measurability of information quality. Journal of the American Society for Information Science and Technology, 62(1), 89-99.

Arazy, O., Kopak, R., \& Hadar, I. (2017). Heuristic Principles and Differential Judgments in the Assessment of Information Quality. Journal of the Association for Information Systems, 18(5), 403-432. 
Volume 6 Issue 24 (December 2021) PP. 34-57 DOI: 10.35631/JISTM.624005

Ashrafi, A., \& Ravasan, A. (2018). How market orientation contributes to innovation and market performance: the roles of business analytics and flexible IT infrastructure. Journal of Business \& Industrial Marketing, 33(7), 970-983.

Bossé, É., \& Rogova, G. L. (Eds.). (2019). Information Quality in Information Fusion and Decision Making. Switzerland: Springer.

Breakspear, A., 2013. A new definition of intelligence. Intelligence National Security, 28 (5), 678-693.

Calof, J. (2017). Canadian competitive intelligence practices-a study of practicing strategic and competitive intelligence professionals Canadian members. Foresight, 19(6), 577589.

Calof, J., \& Sewdass, N. (2020). On the relationship between competitive intelligence and innovation. Journal of Intelligence Studies in Business, 10(2), 32-43.

Calof, J., Arcos, R., \& Sewdass, N. (2018). Competitive intelligence practices of European firms. Technology Analysis \& Strategic Management, 30(6), 658-671.

Chin, W. W. (2010). How to write up and report PLS analyses. In: Vinzi, V.E., Chin, W. W., Henseler, J. \& Wang, H. (Eds.), Handbook of Partial Least Squares, first ed. Springer, Berlin, pp. 655-690.

Chummun, B. Z., \& Singh, A. (2019). Factors Influencing the Quality of Decision-Making Using Business Intelligence in a Metal Rolling Plant in KwaZulu-Natal. Journal of Reviews on Global Economics, 8, 1108-1120.

Dabrowski, D. (2018). Sources of Market Information, Its Quality and New Product Financial Performance. Engineering Economics, 29(1), 115-122.

Daft, R. L., Sormunen, J., \& Parks, D. (1988). Chief executive scanning, environmental characteristics, and company performance: An empirical study. Strategic Management Journal, 9(2), 123-139.

Daradkeh, M., \& Moh'd Al-Dwairi, R. (2018). Self-Service Business Intelligence Adoption in Business Enterprises: International Journal of Enterprise Information Systems, 13(3), 65-85.

DeLone, W. H., \& McLean, E. R. (1992). Information systems success: The quest for the dependent variable. Information Systems Research, 3(1), 60-95.

DeLone, W. H., \& McLean, E. R. (2003). The DeLone and McLean model of information systems success: a ten-year update. Journal of Management Information Systems, 19(4), 9-30.

Du Toit, A. S. (2015). Competitive intelligence research: An investigation of trends in the literature. Journal of Intelligence Studies in Business, 5(2), 14-21.

Falahat, M., Ramayah, T., Soto-Acosta, P., \& Lee, Y. Y. (2020). SMEs internationalization: The role of product innovation, market intelligence, pricing and marketing communication capabilities as drivers of SMEs' international performance. Technological Forecasting and Social Change, 152, 1-7.

Fornell, C. \& Larcker, D. (1981). Evaluating structural equation models with unobservable variables and measurement error. Journal of Marketing Research, 18(1), 39-50.

Gorla, N., Somers, T. M., \& Wong, B. (2010). Organizational impact of system quality, information quality, and service quality. The Journal of Strategic Information Systems, 19(3), 207-228. 
Hair, J. F., Hult, G. T. M., Ringle, C. M., \& Sarstedt, M. (2014). A primer on partial least squares structural equation modeling (PLS-SEM). Thousand Oaks: Sage Publications. Retrieved from http://www.sagepub.com/books/Book237345

Hair, J. F., Risher, J. J., Sarstedt, M., \& Ringle, C. M. (2019). When to use and how to report the results of PLS-SEM. European Business Review, 31(1), 2-24.

Hanif, N., Arshed, N., \& Farid, H. (2021) Competitive intelligence process and strategic performance of banking sector in Pakistan. J. Business Information Systems, 1-24.

Hendar, H., Ratnawati, A., Ab Razak, W. M. W., \& Abdullah, Z. (2020). Market intelligence on business performance: The mediating role of specialized marketing capabilities. Journal of Intelligence Studies in Business, 1(1), 42-58.

Henseler, J., Ringle, C. M., \& Sarstedt, M. (2015). A new criterion for assessing discriminant validity in variance-based structural equation modeling. Journal of the academy of marketing science, 43(1), 115-135.

Jaklič, J., Coelho, P. S., \& Popovic, A. (2009). Information quality improvement as a measure of business intelligence system benefits. WSEAS Transactions on Business and Economics, 6(9), 502-512

Jaklič, J., Grublješič, T., \& Popovič, A. (2018). The role of compatibility in predicting business intelligence and analytics use intentions. International Journal of Information Management, 43(-), 305-318.

Ji-fan Ren, S., Fosso Wamba, S., Akter, S., Dubey, R., \& Childe, S. J. (2017). Modelling quality dynamics, business value and firm performance in a big data analytics environment. International Journal of Production Research, 55(17), 5011-5026.

Key, T. M., \& Challagalla, G. (2020). Information transparency as competitive advantage: research approaches to platform ecosystem design and competition. AMS Review, 1-3.

Kohli, A. K., \& Jaworski, B. J. (1990). Market orientation: the construct, research propositions, and managerial implications. The Journal of Marketing, 54(-), 1-18.

Köseoglu, M. A., Mehraliyev, F., Altin, M., \& Okumus, F. (2020). Competitor intelligence and analysis (CIA) model and online reviews: integrating big data text mining with network analysis for strategic analysis. Tourism Review, DOI: 10.1108/TR-102019-0406.

Köseoglu, M. A., Morvillo, A., Altin, M., De Martino, M., \& Okumus, F. (2019). Competitive intelligence in hospitality and tourism: a perspective article. Tourism Review, 28, 690710.

Köseoglu, M. A., Ross, G., \& Okumus, F. (2016). Competitive intelligence practices in hotels. International Journal of Hospitality Management, 53 (-), 161-172.

Kumar, V., Saboo, A. R., Agarwal, A., \& Kumar, B. (2020). Generating competitive intelligence with limited information: a case of the multimedia industry. Production and Operations Management, 29(1), 192-213.

Kyoon Yoo, D. (2014). Substructures of perceived knowledge quality and interactions with knowledge sharing and innovativeness: a sensemaking perspective. Journal of Knowledge Management, 18(3), 523-537.

Laumer, S., Maier, C., \& Weitzel, T. (2017). Information quality, user satisfaction, and the manifestation of workarounds: a qualitative and quantitative study of enterprise content management system users. European Journal of Information Systems, 26(4), 333-360.

Lee, Y. W., Strong, D. M., Kahn, B. K., \& Wang, R. Y. (2002). AIMQ: a methodology for information quality assessment. Information \& Management, 40(2), 133-146. 


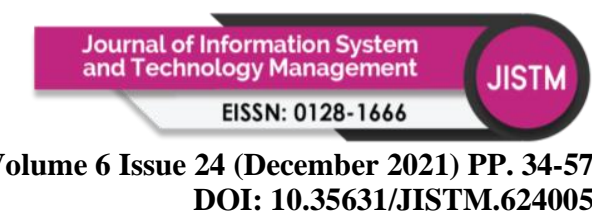

Lutz, C. J., \& Bodendorf, F. (2020). Analyzing industry stakeholders using open-source competitive intelligence-a case study in the automotive supply industry. Journal of Enterprise Information Management, 33(3), 579-599.

Madureira, L., Popovič, A., \& Castelli, M. (2021). Competitive intelligence: A unified view and modular definition. Technological Forecasting and Social Change, 173, 121086.

MAH, Malaysia, 31 December, 2018. Available from: http://www.hotels.org.my/directories.html.

Maritz, R., \& du Toit, A. (2018). The practice turn within strategy: Competitive intelligence as integrating practice. South African Journal of Economic and Management Sciences, 21(1), 1-14.

Marshall, L., \& De la Harpe, R. (2009). Decision making in the context of business intelligence and data quality. South African Journal of Information Management, 11(2), 1-15.

Mitrovic, S. (2020). Adapting of International Practices of Using Business-Intelligence to the Economic Analysis in Russia. In Digital Transformation of the Economy: Challenges, Trends and New Opportunities (pp. 129-139). Switzerland: Springer, Cham.

Mohamad, N. H., Shabani, M., \& Woods, P. C. (2018). Competitive Intelligence Awareness in Creative Multimedia Industry in Malaysia. Advanced Science Letters, 24(2), 10221026.

Mohammed, A. A., Rashid, B. B., \& Tahir, S. B. (2017). Customer relationship management and hotel performance: the mediating influence of marketing capabilities-evidence from the Malaysian hotel industry. Information Technology \& Tourism, 17(3), 335361.

Nasri, W. (2011). Competitive intelligence in Tunisian companies. Journal of Enterprise Information Management, 24(1), 53-67.

Noor, N. A. M., \& Kumar, D. (2014). ECO friendly 'activities' VS ECO friendly 'attitude': Travelers intention to choose green hotels in Malaysia. World Applied Sciences Journal, 30(4), 506-513.

Oraee, N., Sanatjoo, A., \& Ahanchian, M. R. (2020). The competitive intelligence diamond model with the approach to standing on the shoulders of giants. Library \& Information Science Research, 42(2), 1-12.

Pellissier, R., \& Nenzhelele, T. E. (2013). Towards a universal competitive intelligence process model. South African Journal of Information Management, 15(2), 1-7.

Petter, S., DeLone, W., \& McLean, E. R. (2013). Information systems success: The quest for the independent variables. Journal of Management Information Systems, 29(4), 7-62.

Radzi, S. M., Yasin, M. F. M., Zahari, M. S. M., Ahmat, N. H. C., \& Ong, M. H. A. (2017). Moderating Effects of Environmental Variables on the Relationship Between BOS and Performance of Four and Five Star Hotels in Kuala Lumpur, Selangor, and Putrajaya, Malaysia. Advanced Science Letters, 23(11), 10830-10833.

Saayman, A., Pienaar, J., de Pelsmacker, P.J., Viviers, W., Cuyvers, L., Muller, M.-L., \& Jegers, M. (2008). Competitive Intelligence: Construct exploration, validation and equivalence. Aslib Proceedings: New Information Perspectives, 60(4), 383-411.

Saleh, M. H. M., Azmin, A. A., \& Saraih, U. N. EFFECT OF MARKETING ETHICS AS A MODERATE ON THE RELATIONSHIP BETWEEN MARKET ORIENTATION AND SME PERFORMANCE: EVIDENCE FROM SAUDI ARABIA. International Journal of Entrepreneurship and Management Practises (IJEMP), 14(4), 13-29.

Saleh, M. H. M., Azmin, A. A., \& Saraih, U. N. THE EFFECT OF MARKETING ETHICS AS A MODERATOR ON THE RELATIONSHIP BETWEEN CUSTOMER 


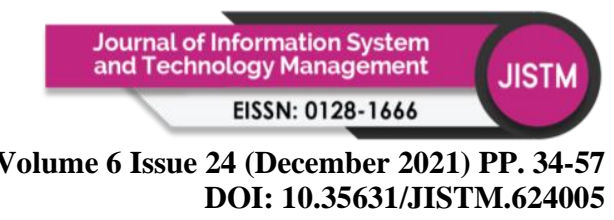

ORIENTATION AND SMES PERFORMANCE IN SAUDI ARABIA. Advanced International Journal of Business, Entrepreneurship and SME's (AIJBES), 8(3), 119138.

Saleh, Moad Hamod M., Adi Anuar Azmin, and Ummi Naiemah Saraih. "THE EFFECTS OF MARKET ORIENTATION, PRODUCT INNOVATION AND MARKETING ETHICS ON FIRM PERFORMANCE: A THEORETICAL FRAMEWORK.". International Journal of Innovation and Industrial Revolution (IJIREV), 7(3), 31-47.

Salguero, G. C., Gámez, M. Á. F., Fernández, I. A., \& Palomo, D. R. (2019). Competitive Intelligence and Sustainable Competitive Advantage in the Hotel Industry. Sustainability, 11(6), 1-12.

Salguero, G. C., Resende Jr, P. C., \& Fernández, I. A. (2017). Proposal of an assessment scale in competitive intelligence applied to the tourism sector. Journal of Intelligence Studies in Business, 7(2), 38-47.

Saxena, D., \& Lamest, M. (2018). Information overload and coping strategies in the big data context: Evidence from the hospitality sector. Journal of Information Science, 44(3), 287-297.

SCIP (2009). Social Citizenship Indicator Program database homepage. Available at Available at https://dspace.it.su.se/dspace/handle/10102/7. (last accessed 18 January 2009).

Sekaran, U. and Bougie, R. (2016), Research Methods for Business: A Skill Building Approach, John Wiley \& Sons, Queensland.

Setia, P., Setia, P., Venkatesh, V., \& Joglekar, S. (2013). Leveraging digital technologies: How information quality leads to localized capabilities and customer service performance. Mis Quarterly, 37(2), 565-590.

Seyyed-Amiri, N. A. D. E. R., Shirkavand, S., Chalak, M., \& Rezaeei, N. (2017). Competitive intelligence and developing sustainable competitive advantage. AD-Minister, 30(-), 173-194.

Shen, C. C., Chang, R. E., Hsu, C. J., \& Chang, I. C. (2017). How business intelligence maturity enabling hospital agility. Telematics and Informatics, 34(1), 450-456.

Silva, P. M. (2021). Examination in B2B trade show: the effects of competitive intelligence and the information management system on the exhibitor's marketing strategy. Journal of Marketing Analytics, 1-14.

Sin, K. Y., \& Jusoh, M. S. (2019). Identifying and Prioritizing Research Gaps in Studies related to Total Quality Management on Competitive Advantage in Malaysian Hotel Industries. INTERNATIONAL JOURNAL OF ACADEMIC RESEARCH IN BUSINESS AND SOCIAL SCIENCES, 9(5), 335 - 349.

Søilen, K. S. (2017). Why care about competitive intelligence and market intelligence? The case of Ericsson and the Swedish Cellulose Company. Journal of Intelligence Studies in Business, 7(2), 27-39.

Stonier, T. (1991). Towards a new theory of information. Journal of Information Science, 17(5), 257-263.

Tao, Q., \& Prescott, J. E. (2000). China: Competitive intelligence practices in an emerging market environment. Competitive Intelligence Review, 11(4), 65-78.

Tej Adidam, P., Banerjee, M., \& Shukla, P. (2012). Competitive intelligence and firm's performance in emerging markets: an exploratory study in India. Journal of Business \& Industrial Marketing, 27(3), 242-254.

Teo, T. S., \& Choo, W. Y. (2001). Assessing the impact of using the Internet for competitive intelligence. Information \& Management, 39(1), 67-83. 


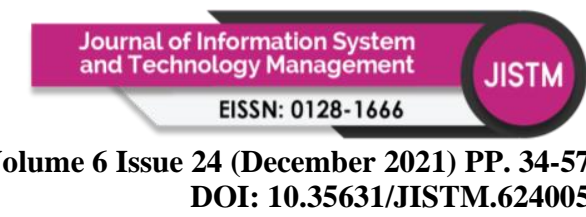

Torres, R., \& Sidorova, A. (2019). Reconceptualizing information quality as effective use in the context of business intelligence and analytics. International Journal of Information Management, 49, 316-329.

Tourism Malaysia (2020) Tourism Malaysia-statistics. Retrieved 10 Jul 2020 from: https://www.tourism.gov.my/statistics.

Valerie, F. (2012). Re-discovering the PLS approach in management science. M@n@gement, 15(1), 101-123.

van den Berg, L., Coetzee, B., \& Mearns, M. (2020). Establishing competitive intelligence process elements in sport performance analysis and coaching: A comparative systematic literature review. International Journal of Information Management, 52, 102071.

Visinescu, L. L., Jones, M. C., \& Sidorova, A. (2017). Improving decision quality: the role of business intelligence. Journal of Computer Information Systems, 57(1), 58-66.

Vugec, D. S., Vukšić, V. B., Bach, M. P., Jaklič, J., \& Štemberger, M. I. (2020). Business intelligence and organizational performance. Business Process Management Journal, DOI 10.1108/BPMJ-08-2019-0342.

Wamba, S. F., Akter, S., Trinchera, L., \& De Bourmont, M. (2019). Turning information quality into firm performance in the big data economy. Management Decision, 57(8), 1756-1783.

Watson, H. J., Goodhue, D. L., \& Wixom, B. H. (2002). The benefits of data warehousing: why some organizations realize exceptional payoffs. Information \& Management, 39(6), 491-502.

Wieder, B., \& Ossimitz, M. L. (2015). The impact of Business Intelligence on the quality of decision making-a mediation model. Procedia Computer Science, 64(-), 1163-1171.

Wieder, B., \& Ossimitz, M. L. (2019, May). Management Accounting Information Quality and Firm Performance-the Enabling Role of Business Intelligence and Analytics Systems. In 1OTH EIASM CONFERENCE ON PERFORMANCE MEASUREMENT AND MANAGEMENT CONTROL. https://opus.lib.uts.edu.au/handle/10453/132901

Wright, S., Eid, E. R., \& Fleisher, C. S. (2009). Competitive intelligence in practice: empirical evidence from the UK retail banking sector. Journal of Marketing Management, 25(910), 941-964.

Yadegaridehkordi, E., Nilashi, M., Shuib, L., Nasir, M. H. N. B. M., Asadi, S., Samad, S., \& Awang, N. F. (2020). The impact of big data on firm performance in hotel industry. Electronic Commerce Research and Applications, (40), 1-33.

Yan-Li, B., \& He-feng, H. (2015, December). Research on evaluation index system of tourist hotels' competitive intelligence ability. In Computer Science and Network Technology (ICCSNT), 2015 4th International Conference on (Vol. 1, pp. 495-499). IEEE, December 19-20, 2015, Harbin, China.

Yan-Li, B., \& He-feng, H. (2016, October). Framework and management of competitive intelligence system for tourist hotels in the era of big data. In Computer and Communications (ICCC), 2016 2nd IEEE International Conference on (pp. 60-64). IEEE,Oct. 14-17, 2016, Chengdu, China, 60-64.

Yap, C. S., Cheng, B. L., \& Choe, K. L. (2014). Web 2.0 as a tool for market intelligence acquisition in the Malaysian hotel industry. Information Research, 19(4), 55-70

Yap, C. S., Cheng, B. L., Mohamad Hussain, N., \& Ahmad, R. (2018). Innovativeness, market intelligence practices, and firm performance of small-and medium-sized tour operators. Tourism and Hospitality Research, 18(2), 143-151. 
Volume 6 Issue 24 (December 2021) PP. 34-57 DOI: 10.35631/JISTM.624005

Yin, C. Y. (2018). Measuring organizational impacts by integrating competitive intelligence into executive information system. Journal of Intelligent Manufacturing, 29(3), 533547.

Zikmund, W. G. (2003). Sample designs and sampling procedures. Business Research Methods, 7(2), 368-400.

Zikmund, W. G., Babin, B. J., Carr, J. C., \& Griffin, M. (2013). Business research methods (9th edition). SOUTH-WESTERN, USA: Cengage Learning. 